\title{
“There was sex but no sexuality 1:" Critical Cataloging and the Classification of Asexuality in LCSH
}

Brian M. Watson

Department of Information and Library Science, Indiana University Bloomington, Bloomington, United States of America

briwats@iu.edu

1 Phillips, Kim M., and Barry Reay. Sex before Sexuality: A Premodern History. Themes in History. Cambridge, UK; Malden, MA, USA: Polity, 2011, 6-7. 


\section{"There was sex but no sexuality:" 1 Critical Cataloging and the Classification of Asexuality in LCSH}

This paper examines the addition of 'asexuality' to the Library of Congress Subject Headings as a case study from which to examine the critical cataloging movement. Beginning with a review of some of the theoretical and practical issues around subject access for minoritized and marginalized sexualities, this paper then contextualizes, historicizes, and introduces the critical cataloging movement to the literature, situating it within a larger and longer history of radical cataloging. It will define critical cataloging as a social justice oriented style of radical cataloging that places an emphasis on radical empathy, outreach work, and recognizes the importance of information maintenance and care. This paper introduces the concept of "catalogic warrant" to characterize the process of "reading" the catalog in order to examine the harm or benefit of terms on users and the wider library community.

Keywords: asexuality; radical cataloging; critical cataloging; Library of Congress Subject Headings; catalogers; subject cataloging

\section{Introduction}

In the summer of 2016, the typically-overlooked work of cataloging and classification became the work of national politics. That March, the United States Library of Congress (LC) announced the planned cancellation of the subject headings "Illegal Aliens" and "Illegal Immigration" and their replacement with "Noncitizens" and "Unauthorized immigration" in the LC Subject Headings (LCSH).2 In June, the Republican-led House of Representatives inserted a provision into an Appropriations Bill that instructed LC to not change the heading. Even though this provision did not survive the Senate, LC bowed to political pressure and allowed the headings 'illegal' and 'alien' to continue discrediting the catalog-a decision that could be reversed at any time LC chooses to do so.3 For many Americans, this likely seemed like a strange political episode in an already-strange year. American librarians, or those familiar with library work likely found themselves agreeing with 
the words of Congresswoman Debbie Wasserman Schultz, who noted in a speech that the Library of Congress

changes thousands of subject headings each year without interference from Congress. Why this one? Why now? ...the library is in the business of language and nomenclature, and should be free to make these decisions without political interference.4

For catalogers, however, this demonstration of the political nature of "the power to name," likely echoed a much longer history, dating back nearly a century. There is even a marked similarity in the tactics used by present-day catalogers and the work of earlier ones like Sandy Berman and the ALA Task Force on Gay Liberation in the 1960s and 70s.5

As the struggle over "Illegal Alien" is still ongoing,* and has been discussed at greater depth elsewhere, this paper will instead focus on another pair of terms that were, through a series of coincidences, silently paired with “Noncitizen” and “Unauthorized Immigration.” In March of 2016, the same time LC initially announced the cancellation of "Illegal Aliens" and "Illegal Immigration" it also considered and rejected a proposal for the addition of "Asexuality" and "Asexual People" to LCSH. Then, in July, Asexuality was approved at the same time that LC was reversing its cancellation decision. The fact that asexuality, which is still treated with skepticism in some professional domains (such as the American Psychological Association's Diagnostic and Statistical Manual), passed official examination with barely a ripple, whereas similar revisions decades earlier triggered nearly as strong reactions provokes the same question that Representative Wasserman Schultz asked: "Why this [term]? Why now?"

In order to answer this question, this paper will situate the critical cataloging effort within the larger library and information science (LIS) literature. It will begin with a review of some of the theoretical and practical issues around LGBTQIA2S+ (henceforth queer) subject access facing

\footnotetext{
* Indeed, as this paper was being revised-in June of 2020 - the Association for Library Collections \& Technical Services, Cataloging and Metadata Management Section issued a working group report on alternatives to "Illegal Aliens" and how libraries across the country were addressing revisions locally. See Violet Fox et al., "Report of the SAC Working Group on Alternatives to LCSH 'Illegal Aliens,'” Report (Subject Analysis Committee, June 19, 2020), https://alair.ala.org/handle/11213/14582.
} 
members of the community, as well as catalogers. Following that, this paper then contextualizes, historicizes, and introduces the critical cataloging movement to the literature, situating it within a larger and longer history of radical cataloging. It will define critical cataloging as a social justice oriented style of radical cataloging that places an emphasis on radical empathy, outreach work, and recognizes the importance of information maintenance and care. Rather than bibliographic warrant, critical catalogers read cataloging and classification systems with an eye for catalogic warrant, reflecting on the potential harm or benefit of each term on the catalog, users, and the library community as a whole. Critical catalogers understand the catalog in a "holistic manner," and see systems like the Library of Congress or Dewey Decimal Classification as living documents that can be revised and improved.6 The remainder of the text will focus on one such improvement: the addition of "Asexuality" and "Asexual people" to the LCSH.

\section{Literature Review}

\section{Sexuality and Issues in its Cataloging and Classification}

Researchers such as Melissa Adler7, Hope Olsen8, Ellen Greenblatt9, Erin Baucom10, K.R. Roberto11, Analisa Ornelas12 and others 13 have illustrated the fallacies, inconsistencies, failures, mistakes, and incorrect information contained in LCSH, especially around gender and queer sexualities. Drawing on the work of Michel Foucault and Eve Kovosky Sedgwick, these scholars argue that the top-down essentialist classification of queer sexualities does not reflect the understandings of queer communities and that under- or misrepresentation in and by catalogs can be marginalizing. For example, before the events discussed below, the preferred identity term 'asexuality' or 'asexual' returned results about "Plants-Reproduction, Asexual."

Additionally, some have proffered solutions directly relevant to subject catalogers, such as Rawson14, Nichols and Cortez15, and Nowak and Mitchell16, who have suggested the creation of alternative vocabularies, ontologies, and taxonomies (respectively) to address these problems. It remains unclear how these systems would grapple with the issues that Ben Christensen identified 
in his 2008 article “'Minoritization vs. Universalization," which points out that queer-specific terminology is prone to a definitional vagueness and shifting definition (a queerness, in other words).17 J. L. Colbert's remarkable 2017 study demonstrates that even highly-educated doctorallevel researchers do not depend upon or use subject headings in their research process, and indicates that subject access "should also consider other forms of access, such as local headings or tagging systems." 18 Indeed, the most significant branch of proposed solutions (by Adler19, Ornelas20, Wexelbaum21, and Bates and Renley22) have also advocated for the development and use of tagging folksonomies, especially for queer material. However, as Keilty convincingly argues, tagging and folksonomies

are not free of disciplinary forces; they are not entirely free of control...however productive folksonomies are for counteracting 'information imperialism,' and however productive they are for retrieving information, they are also highly regulatory." 23

This is not to say that folksonomies cannot be useful, powerful, or emancipatory. However, it does mean that any community-developed term is problematized by the fact that it exists within the society that minoritized that community. Additionally, as Gross, Taylor and Joudrey have demonstrated, there is "still a lot to lose:" the removal of controlled vocabularies from catalogs results in the loss of nearly thirty percent of the hits in a keyword search, which would have a deleterious impact on users.24

Over the past few years, however, the cataloging literature has reflected a growing realization of bias that verges on abnegation. As Crystal Vaughan puts it, prejudices still exist and "will always exist in taxonomies because language systems are representative rather than definitive." 25 As she explains:

when classifications are created, they inherently reflect the predominant biases of society...To categorize something is to define what it is not, yet what something is or is not is subject to change depending on the socio-political climate. Consequently, representation is a fluid construction. 26

Emily Drabinski argued among similar lines in her now-classic article "Queering the Catalog: Queer 
Theory and the Politics of Representation,"

[this] movement has addressed the problem of bias in these structures primarily as a functional problem: materials are cataloged incorrectly, and they can be cataloged correctly with the correct pressure from activist catalogers.27

Drabinski argues that historical terms-even ones considered offensive today-should remain in catalog. The "correction" should instead take place through the use of education and contextualization by library educators.

Though this is a persuasive argument in theory, it would be challenging (not to mention expensive) to implement in practice, as it would require the hiring of a significant number of additional staff to mediate patron experience with catalogs, and would be even harder to implement outside of an academic library context. Furthermore, as Paige Crowl, now a librarian at Emory University, documented in an essay for her MLIS coursework, it is not always possible for a librarian to intervene in a user's experience of a catalog. While attempting to discover something about her own asexuality, Crowl searched "frantically" through her university catalog, but found that her search results pointed only to

biological works on asexual reproduction and psychological works on disorders of sexual desire. I was too embarrassed to ask a librarian for help, unsure I could even explain the information need I had to myself, I gave up on my search and slunk away in defeat. I had no idea then that I had just reenacted the timeless experience of users looking for queer materials in libraries across many decades: misunderstanding, pathologizing, shame, and defeat. Queer materials are infamously difficult to find, especially for inexperienced searchers.28

Crowl's experience is a microcosm of the previously-discussed literature: queer library users face special barriers to access and the subject cataloging process is especially difficult for queer material. These issues are compounded by the fact that asexual individuals live in a society that is, by best estimates, 99\% allosexual—which will be touched on in further detail below. These are deeply unsatisfying answers, and give the impression of a field at an impasse. Working catalogers and technical staff, many of whom are under-acknowledged, overworked, and underpaid cannot 
wait around for clear 'solutions' to be developed-nor have they. The most substantive reaction was the development of the radical cataloging (RADCAT) movement, which will be discussed below.

\section{Radical and Critical Catalogs}

Although many - such as Francis Yocom and Dorothy Porter in the 1940s — had articulated issues with the Western and white-centric nature of cataloging and classification before the 1970s, widespread scholarly discussion did not begin to develop until after the publication of Sanford “Sandy” Berman's 1971 book Prejudices and Antipathies: A Tract on the LC Subject Heads Concerning People.29 Berman, perhaps the best-known radical cataloger, began his campaign after the experience of working in Zambia as a librarian, where he was told that the term kaffir-present in LCSH as a 'neutral' descriptor-was considered a particularly racist slur.30 The result of his investigation was the aforementioned Tract, which amounted to a full-fledged attack on the racist, sexist, and Eurocentric nature of LCSH. Berman, alongside other activists, including the Poor People's Campaign and the American Library Association's Task Force on Gay Liberation, worked from within the cataloging world to pressure change in the LCSH, with varying levels of success. By 2012, Berman's personal LCSH 'scorecard' documented nearly 100 accepted revisions or proposals alongside over 200 that LC had rejected or not yet acted upon.31

Berman's initial documentation of LC's "insidious labelling processes" initiated a nearcontinuous tradition of librarians and catalogers re-reading of subject terms with an eye towards revision. 32 It also undoubtedly contributed to the founding of the LC's Program for Cooperative Cataloging (PCC) in 1992, as well as the Policy and Standards Division which effectively institutionalized a process previously conducted via public petition and political remonstrance.† Today, a number of radical catalogers continue their work and discussion through an eponymous

\footnotetext{
† Again, the author is thankful to Violet B. Fox for this observation and for her critique of an earlier version of this article.
} 
listserv hosted at the University of Georgia (radcat@listserv.uga.edu), and have expanded the meaning of RADCAT to include things such as

being user-focused with regard to your library's users...having a healthy dose of skepticism about the quality of readily available bibliographic records, but choosing to improve their quality... realizing that copy cataloging can be just as difficult and complicated as original cataloging... knowing when and how to make cataloging decisions that may be in conflict with traditional cataloging standards... feeling passionate about cataloging and its benefits [and more].33

Disappointingly, aside from the 2008 collection of essays quoted from here, there has been minimal discussion in the literature on these topics. For example, a search of Cataloging \& Classification Quarterly for "radical cataloging" returns only a review of Radical Cataloging: Essays at the Front along with references to that volume.34 Searches for the same term in Google Scholar and other academic indexes returns similar results. Likewise, searches for "critical cataloging," the focus of this article, returns only references to Hope Olsen's 1994 article “Teaching Critical Cataloging,” (which will be discussed below), along with an article by Suzhen Chen and Margaret Joyce detailing the process of teaching critical cataloging, a topic which is outside the scope of this discussion. 35

Given the demonstrable impacts that the CritCat effort has already had on national and international discussion, the remainder of this paper seeks to fill this literature gap by documenting the process that a group of critical catalogers underwent to have "Asexuality" and "Asexual people" added to the Library of Congress Subject Headings. With the possible exception of Anna M. Ferris' recent discussion on the "complex yet highly gratifying process," by which terms are added to LCSH, no prior studies have examined this process from start to finish.36 While Ferris' examination of the paths that an accepted and a rejected subject heading is highly instructive, it does not explore the organization occurring behind the scenes, as this paper will do below. Furthermore, Ferris' proposed revisions originated out of the typical bibliographical warrant procedure and she is not critical of the LC's process: she concludes on a note of approval, remarking that the "LCSH 
mechanism for creating and maintaining the largest controlled vocabulary system in the world will remain still unsurpassed." 37

While all CritCatters could be considered radical catalogers, not all radical cataloging would necessarily be considered critical. In cataloging terms, CritCat is a NT (Narrower Term) of RADCAT. Like RADCAT, critical catalogers approach traditional cataloging methods, practices, and terms from a novel direction. However, they inherit their philosophical framework from critical librarianship (\#CritLib on Twitter), which, in the words of Toni Samek, places "the human condition and human rights above other professional concerns." ${ }_{38}$ Critical librarians and critical catalogers both use a social justice oriented lens to "expose and challenge the ways that libraries and the profession consciously and unconsciously support systems of oppression." Speaking generally, critical catalogers tend to recognize that that no system is free of bias and tend to inherit a revisionist (rather than an abolitionist) ethos from their RADCAT predecessors. Practices of "radical empathy" 39 , "outreach work," 40 and recognition of the importance of information "maintenance" and "care" 41 are a common thread through CritCat literature and discussion.

While library catalogers typically operate from a position of bibliographic warrant (i.e. cataloging a book that they are holding in their hand), critical catalogers operate from a position of catalogic warrant. By reading and examining subject headings and classification schema from a social justice oriented perspective, catalogic warrant reflects on the potential harm or benefit of each term on users and the library community as a whole. Critical catalogers understand the catalog in a "holistic manner," and see systems like the Library of Congress or Dewey Decimal Classification as living documents that can be revised and improved.42 The remainder of this article will focus on one such improvement—-the recognition of "Asexuality" and "Asexual people." 


\section{The Ace Case}

A pair of mishaps preceded and necessitated the intervention of critical catalogers described below. The first was more of a historical accident: the 'failure' of asexuality to be introduced into the Library of Congress Subject Headings at an earlier point in the system's history. As Melissa Adler recently described in Cruising the Catalog, a significant number of sexuality classifications and terms were imported or adopted into LCSH in the early parts of the twentieth century.43 For whatever reason, asexuality was not one of them, despite its near-continuous discussion in psychological and sexological literature since the nineteenth century. Indeed, asexuality was first described alongside concepts of what would later be called homosexuality and transgenderism in Richard von Krafft-Ebing's extensive catalog of sexual perversions and disorders Psychopathia Sexualis. 44 The word itself was coined shortly thereafter, in 1896, from the Latin prefix ' $a$ ' (meaning not) and 'sexualis,' resulting in a meaning of literally not-sexual, and was used in a number of literary and historical works over the course of the twentieth century.45

The second event of note was a breakdown in Program for Cooperative Cataloging policy. When Anthony F. Bogaert, Professor of Psychology and of Community Health Sciences at Brock University, published Understanding Asexuality (2012), it was given Library of Congress Catalogingin-Publication Data as "1. Sex. 2. Gender Identity," even though the book is not strictly about either of those things.46 Cataloging policy since the 1991 Airlie House Conference requires the use of a more precise subject heading, but Understanding Asexuality's CIP data was authenticated as a full PCC record by catalogers at Yale.47 It is likely not possible to discover the reason for this decision or mistake (and this is not meant as a condemnation of already-overtaxed and understaffed technical services departments). Even though Bogaert's book effectively established asexuality as an important identity category and research topic for several fields, it apparently did not generate the literary warrant necessary for the creation of a new subject heading. This is not the result of a

‡ The author is indebted to an anonymous reviewer for this observation. 
lack of definitional clarity, although there is naturally minor definitional variation in the literature about asexuality. Bogaert, for example, defines asexuality as a "lack of sexual attraction toward both men and women," whereas the Asexuality Visibility and Education Network (AVEN, the world's largest asexuality resource) considers an asexual person to be "simply someone who does not experience sexual attraction. That's all there is to it." 48

The lack of an "Asexuality" subject heading was first raised in 2014 by Jenna Freedman, the Associate Director of Communications and Zine Librarian at Barnard College Library. On her blog Lower East Side Librarian, a hub of the critical cataloging world, Freedman often discusses the limits and pains of using LCSH when cataloging zines. The item that caused her complaint was the 2012 zine Taking the cake: an illustrated primer on asexuality, by Maisha. According to the blog post, Freedman realized that there was no heading for asexuality and wrote an email to the Library of Congress:

It would be helpful if there was a subject heading for Asexuality or Asexuals. I'm prompted to suggest this heading for a zine called Taking the Cake: an Illustrated Primer on Asexuality.

There is a Wikipedia entry for the topic, created in 2002 and over 1 million internet results returned on a search for < asexuality $>$. The most relevant result from the LC catalog is Understanding Asexuality 49.

It is not clear to whom the email was addressed, and it does not seem that this initial request was ever acted upon or acknowledged. The next event in the term's history occurred in January of 2016. According to Netanel Ganin (then a cataloger at Brandeis University), Catherine Oliver (then the Metadata \& Cataloging Services Librarian at Northern Michigan University) "floated the idea of us tag-teaming Asexuality and Asexual people as LCSH proposals." 50 Judging by resulting events, it seems that they agreed to split the work: Ganin would be responsible for "Asexual people" and Oliver for "Asexuality." As Ganin was not at the time a member of LC's Program for Cooperative Cataloging-a program where participants "contribute high quality records and subject proposals conforming to approved standards" ${ }_{51}$ - he submitted the proposal for "Asexual people" through 
"the non-SACO proposal form\&, and then followed up with an e-mail." 52 These events illustrate the argument made earlier: while library catalogers typically operate from a position of bibliographic warrant (i.e. cataloging a book that they are holding in their hand), critical catalogers are not necessarily doing so. In this case, it seems that Oliver and Ganin began their work after discussing the lack of an "Asexuality" term.

According to Ganin, on February 2nd the LC "swept up the heading from the sea and popped it right into the queue [moved it from the form to the consideration queue]," also creating the heading "Asexuality" to complement the proposed class of persons; "Asexual people" was assigned LCCN 2016000237.53 On March 21, the Policy and Standards Division (PSD), the LC division that "provides cataloging and acquisitions policy library wide" and "process[es] subject and classification proposals" 54 met, reviewed, and rejected the proposal—or, in Ganin's words, the proposals were given the "revise and resubmit" status.55 As the PSD's reasoning will be examined below in great detail it is quoted in full here:

In scholarly literature, asexuality is considered to be a sexual identity or a sexual orientation. Also, there is some research that connects asexuality to biological characteristics, so, it could be a biological condition as well. Sexual orientation refers to a biological preference for one or more genders, while asexuals lack any preference. Therefore, Sexual orientation may not be the most appropriate BT [Broader Term] for asexuality. The cataloger might consider using the BT Sex instead.

The heading should be qualified because asexuality is a condition that exists in plants and animals as well as humans, but in plants and animals, it is about sexual expression (i.e., the absence of physical sexual characteristics), rather than desire as it is in humans.

The cataloger should do research in scholarly publications in psychology or the biosciences that give definitions of the terms and provide citations to that research in the proposals. Citations to Wikipedia are not appropriate on these proposals.

The proposals may be resubmitted.56

$\S$ Although Ganin calls it the non-SACO form this is either a mixup or the form has been renamed to the "NonPCC" form. Interested readers may find the non-PCC form on LC's website here:

https://www.loc.gov/catdir/cpso/lcshproposalformnew.pdf 
The first six sentences in the response are revealing and troubling. In that space the response; (1) describes asexuality as a "biological characteristic," a "biological condition," and a "biological preference;" (2) conflates sexual and gender orientation with sexual attraction; (3) suggests that asexuality is a "biological" aspect of an asexual person's nature, rather than an orientation; and (4), unironically raises the connection between asexuality and plants. It is startling - to put it lightlyto see how close the PSD notes come to recalling earlier language of "pathological homosexuality."57

This rejection did not dismay the petitioners, as Ganin and Oliver explained later. Joined by Violet B. Fox (a Dewey Decimal Classification editor) and other catalogers the team "began gathering sources and sources and sources" into a private Google document, a copy of which was graciously provided to the author by Ganin.58 The notes reveal that the group was as puzzled by the PSD's reply as the PSD was by asexuality. Fox outlined the main points that she thought needed to be addressed in the revised proposal. Under the heading: "LC's points of contention (as far as I can tell)," she listed four points:

1. Is asexuality a sexual identity or sexual orientation?

2. Should broader term be Sexual orientation? Or Sex? Perhaps Sex (Psychology)??

3. Does Asexuality need to be qualified? LC says: "because asexuality is a condition that exists in plants and animals as well as humans, but in plants and animals, it is about sexual expression (i.e., the absence of physical sexual characteristics), rather than desire as it is in humans."

4. We need scholarly publications in psychology or the biosciences that give definitions of the terms and provide citations to that research.59

These notes are illuminating, and will be addressed in turn.

First, the shared notes documents the PCC's confusion, and Cataloger $1{ }^{* *}$ sketched out some of the distinctions that should be illustrated in the revised proposal, explaining that:

Asexuality is a sexual orientation. The equivalent-ish sexual identity would be agender. The equivalent-ish romantic orientation would be aromantic. (Some people are transgender, heteroromantic asexuals; some people are cisgender, homoromantic, asexuals. It's mix or

** As I was unable to contact and obtain permission from some other members of the team after several attempts, I have anonymized their comments and removed personally identifying information from this article, choosing only to identify them as Cataloger 1 and Cataloger 2 below. 
match, not equivalent terms.) I can find citations, but honestly the most clearly I've seen this laid out is online in crowdsourced places where members of these communities are talking. (ibid.).

As all of the catalogers agreed with these distinctions, they decided to gather supporting information from a variety of sources in order to pass LC's bar for quality. In grappling with the 'quality' question, one cataloger asked if the board would accept material from GLAAD (a LGBTQIA+ focused non-governmental media organization) or AVEN (the Asexual Visibility and Education Network). Demonstrating the value of cooperation and mutual consensus, another cataloger 'reread' the PSD'd statement, and stated that: “I think they do consider AVEN or GLAAD legit...we just need moar [sic, humorous typo] sources to cite, from a variety of types (and LC is telling us that the type they're looking for is scholarly publications)." 60 In order to satisfy that requirement and substantiate their application, the group referred to Oliver's previous work on "Asexuality."

This cooperative process also helped the group arrive at a consensus in formulating a reply to the second question, about the correctness of the classification. Nearly immediately, they agreed that 'Sex' or 'Sex (Psychology)' was an inappropriate broader term for asexuality as it suggested 'biological' sex. Fox, for example, noted straightaway "I do think Sexual orientation is the correct BT, we just need to find a few resources that are explicit about stating so." Consulting the literature, they ran up against the gap between the biological/scientific definitions and the human orientation that they were attempting to define:

Fox: [PCC's comment] (again) seems a little confusing to me (Violet), as terms like Homosexuality haven't needed a (Human) qualifier, although there have been instances of homosexual behavior in animals?

Cataloger 1: I think they are confusing libido with sexual attraction...

Unknown: Perhaps if we can be more specific about citations that state Asexuality is a sexual orientation... Do medical / psychological / biosciences folks use the term "asexuality" to refer to lack of sexual interest caused by illness/hormonal disturbances? I don't think so, but is that what LC is getting at here??61

From surviving notes it seems that the team considered and rejected other qualifiers such as 'Asexuality (Psychology),' before there was a breakthrough: 
Unknown (Oliver?): From what I'm reading, it looks like we need to differentiate between Asexuality as a characteristic of reproductive practice (as in certain organisms) and Asexuality as a sexual orientation in species that reproduce sexually. I think having Asexuality under Sex actually OBSCURES that difference. Having it under Sexual orientation makes it much clearer. YES, Asexuality (Sexual orientation) -- Catherine [emphasis in the original]

Fox: Great point about the hierarchy, Catherine. --Violet

Cataloger 1: I like this too! 62

It is not clear from their notes when the team examined the catalog entry for "Bisexual People" but in his resubmission, Ganin references the record: "Re-submitting the proposal following the pattern of Bisexuals, but using Asexual people as the $\$ 150$ and Asexuals as the $\$ 450$ to prevent confusion with plants and animals." 63

Ganin resubmitted the proposal on April 18, 2016, but it had to be done via email as he was "unable to edit the master records." 64 The final resubmissions included references to the website WhatIsAsexuality.org and AVEN, as well as 2014 books by Julie Sondra Decker (The Invisible Orientation: an Introduction to Asexuality) and Karli June Cerankowski and Megan Milks (Asexualities: Feminist and Queer Perspectives); both of which had previously been assigned incorrect ("Sexual Attraction" ; "Sex") or the insulting and medically-incorrect subject heading "Sexual desire disorders." 65

\section{Conclusion}

The (re)proposed headings were accepted on May 24, posted to the LC's monthly list of changes in June 20, and then approved for usage on July 13, 2016.66 Ganin celebrated the accomplishment with a tweet:

I know we're celebrating [the election of Carla Hayden as 14th Librarian of Congress] right now, and here's one more congratulations...on getting Asexuality (Sexual orientation) and Asexual people officially approved as new \#LCSH67

This accomplishment is evidence of how critical catalogers read, understand, and work to revise the catalog, as well as their emphasis on cooperation and collaboration. While the road to getting 
"Asexuality" and "Asexual people" added to the Library of Congress Subject Headings is a unique in some ways, such as its 'failure' to transition to LSCH along with many other sexological terminology (the reasons for which will be explored in a later paper), or the authentication of the CIP data, there are likely many successful RADCAT and CritCat revisions that would reveal similar incidences or incorrect historical assumptions.

It is hard to see how LC could have (or can) see all multifarious possibilities and limitations to its Subject Headings, or be more proactive in addressing historical biases. One possibility might be an ongoing practice of reviewing "Subject Heads Concerning People." This practice could be informed by seeing information maintenance as a "Practice of Care" that documents, verifies, and considers "systemic and personal impact." 68 Such a practice would

challenge contemporary workplace attitudes surrounding "productivity" and "efficiency," moving toward the recognition of maintenance itself as a valued contribution. We can also broaden access to systems of information, thereby supporting its generative value.69 Another possibility would be the creation of a Critical Theory SACO Funnel.+† A program of the PCC, SACO funnels are groups of libraries or catalogers that work together to contribute subject authority records for inclusion in LCSH.70 This idea would have the advantages of being efficient as well as building on preexisting infrastructure and policy, and it might also partially answer Matthew Haugen and Amber Billey's recent call to building a more diverse and inclusive cataloging cooperative.71

One argument against such a development, would be that critical cataloging may become a slight misnomer, as the "critical" part of the name derives from the fact that critical theory operates from outside power structures. However, CritCatters have always sought to broaden their work while continuing to participate in larger cataloging and classification systems. These are deliberate

†† I am indebted to an anonymous reviewer for this idea. 
strategies, as a two-part article written by Ganin and Oliver for the blog Concerned Archivists

Alliance demonstrates: the pair explain to readers that all vocabularies reflect "the biases of their creators, contributors, and maintainers," and although LCSH has seen many revisions, it is impossible to escape the fact that it "often centers and treats as the norm (thus unremarked) the white, male, Western, Christian, cishet, abled experience."72 Drawing a social justice oriented ethos that has been elsewhere characterized as "radical empathy,"73 Ganin and Oliver declare that anyone that interacts with metadata can and should contribute to LCSH:

When patrons come to the library or the archives, whether in person or online, they deserve to see themselves represented equitably and equally in the description of our resources, just as they deserve to find themselves represented in the resources themselves. In fact, a lack in the first will often result in the erasure of the second- if the metadata in a finding aid or a catalog record does not use terminology the patron recognizes, or uses terminology the patron finds harmful, the patron is less likely to discover and use the collections. And while local practices are valuable and can enrich metadata, submitting a term to the larger vocabulary has the salutary effect of standardizing it (simplifying matters for frequent users) and making it more useable for metadata creators who may not have the knowledge or time to create local headings of their own.

Michelle Caswell, Marika Cifor, and Mario Ramirez have argued elsewhere that community archives can help minoritized and marginalized individuals "discover themselves existing" and create a profound sense of belonging.74 With the addition of "Asexuality" and "Asexual people" to the catalog, critical catalogers have created a space for those subjects to discover themselves.

\footnotetext{
${ }^{1}$ Kim M. Phillips and Barry Reay, Sex before Sexuality: A Premodern History, Themes in History (Cambridge, UK ; Malden, MA, USA: Polity, 2011), 6-7.

2 Library of Congress, "Library of Congress to Cancel the Subject Heading 'Illegal Aliens,'” Executive Summary (Washington, DC: Library of Congress, 2016), https://www.loc.gov/catdir/cpso/illegal-aliens-decision.pdf. 3 Jasmine Aguilera, "Another Word for 'Illegal Alien' at the Library of Congress: Contentious," The New York Times, July 22, 2016, sec. U.S., https://www.nytimes.com/2016/07/23/us/another-word-for-illegal-alien-at-
} 
the-library-of-congress-contentious.html; Andrew Taylor, "GOP Reinstates Usage of 'illegal Alien' in Library of Congress' Records," PBS NewsHour, May 17, 2016, https://www.pbs.org/newshour/politics/gop-reinstatesusage-of-illegal-alien-in-library-of-congress-records; Lisa Peet, "Library of Congress Drops Illegal Alien Subject Heading, Provokes Backlash Legislation," Library Journal, June 13, 2016, https://www.libraryjournal.com?detailStory=library-of-congress-drops-illegal-alien-subject-headingprovokes-backlash-legislation.

4 Quoted from Sawyer Broadley and Jill Baron, Change the Subject (Dartmouth, New Hampshire, 2019), https://sites.dartmouth.edu/changethesubject/about/.

5 Hope A. Olson, "The Power to Name: Representation in Library Catalogs," Signs: Journal of Women in Culture and Society 26, no. 3 (April 2001): 639-68, https://doi.org/10/dbk3sp; Sanford Berman, Subject Cataloging: Critiques and Innovations (Psychology Press, 1984); Sanford Berman, Joy of Cataloging (Oryx Press, 1981), https://agris.fao.org/agris-search/search.do?recordID=US201300399304; Sanford Berman and Tina Gross, "Expand, Humanize, Simplify: An Interview with Sandy Berman," Cataloging \& Classification Quarterly 55, no. 6 (2017): 347-60, https://doi.org/10.1080/01639374.2017.1327468; Barbara Gittings, "Gays in Library Land: The Gay and Lesbian Task Force of the American Library Association: The First Sixteen Years," in Daring to Find Our Names: The Search for Lesbigay Library History, ed. James V. Carmichael (Wesport, Connecticut: Greenwood Press, 1998), 81-94,

https://books.google.com/books/about/Daring_to_Find_Our_Names.html?id=hfr7Us7PhGkC; James V. Carmichael, "'They Sure Got to Prove It on Me': Millennial Thoughts on Gay Archives, Gay Biography, and Gay Library History," Libraries \& Culture 35, no. 1 (2000): 88-102; Melissa A. Adler, "The ALA Task Force on Gay Liberation: Effecting Change in Naming and Classification of GLBTQ Subjects," Advances in Classification Research Online 23, no. 1 (2012): 1-4, https://doi.org/10.7152/acro.v23i1.14226.

6 Hope A. Olson, "Thinking Professionals: Teaching Critical Cataloguing," Technical Services Quarterly 15, no. 1-2 (September 18, 1997): 52, https://doi.org/10/crn8kr.

7 Melissa Adler and Lindsey M. Harper, "Race and Ethnicity in Classification Systems: Teaching Knowledge Organization from a Social Justice Perspective," Library Trends 67, no. 1 (2018): 52-73,

https://doi.org/10/gfw9tz; Melissa Adler, "Let's Not Homosexualize the Library Stacks': Liberating Gays in the Library Catalog," Journal of the History of Sexuality 24, no. 3 (September 2015): 478-507,

https://doi.org/10/gfwsh3; Melissa Adler, Jeffrey T. Huber, and A. Tyler Nix, "Stigmatizing Disability: Library Classifications and the Marking and Marginalization of Books about People with Disabilities," The Library Quarterly 87, no. 2 (April 2017): 117-35, https://doi.org/10/gft4b3; Melissa Adler, "The Case for Taxonomic Reparations," Knowledge Organization 43, no. 8 (2016): 630-40, https://doi.org/10/gft38p; Melissa Adler, "Transcending Library Catalogs: A Comparative Study of Controlled Terms in Library of Congress Subject Headings and User-Generated Tags in LibraryThing for Transgender Books," Journal of Web Librarianship 3, no. 4 (November 23, 2009): 309-31, https://doi.org/10/fvxmwg; Melissa Adler, Cruising the Library: Perversities in the Organization of Knowledge (New York: Fordham University Press, 2017).

8 Hope A. Olson, "Difference, Culture and Change: The Untapped Potential of LCSH," Cataloging \& Classification Quarterly 29, no. 1-2 (2000): 53-71, https://doi.org/10/dpdr5r; Hope A. Olson, "The Power to Name: Representation in Library Catalogs," Signs: Journal of Women in Culture and Society 26, no. 3 (April 2001): 639-68, https://doi.org/10/dbk3sp; Hope A. Olson, "How We Construct Subjects: A Feminist Analysis," Library Trends 56, no. 2 (2008): 509-41, https://doi.org/10/b99rmj.

9 Ellen Greenblatt, "Homosexuality: The Evolution of a Concept in the Library of Congress Subject Headings," in Gay and Lesbian Library Service, ed. Cal Gough and Ellen Greenblatt, 1990; Cal Gough and Ellen Greenblatt, eds., Gay and Lesbian Library Service (Jefferson, N.C: McFarland, 1990); Ellen Greenblatt, "The Treatment of LGBTIQ Concepts in the Library of Congress Subject Headings," in Serving LGBTIQ Library and Archives Users: Essays on Outreach, Service, Collections and Access, ed. Ellen Greenblatt, 2011, 212-28.

10 Erin Baucom, "An Exploration into Archival Descriptions of LGBTQ Materials," The American Archivist 81, no. 1 (March 2018): 65-83, https://doi.org/10/gft4cf.

11 K.R. Roberto, "Inflexible Bodies Metadata for Transgender Identities," Journal of Information Ethics 20, no. 2 (2011): 56-64, https://doi.org/10/bw6v92; K. R. Roberto, ed., Radical Cataloging: Essays at the Front (Jefferson, N.C: McFarland \& Co, 2008).

12 Analisa Ornelas, "Queer as Folksonomies," in Serving LGBTIQ Library and Archives Users: Essays on Outreach, Service, Collections and Access, ed. Ellen Greenblatt, 2011, 229-39.

13 William N. Schultz and Lindsay Braddy, "A Librarian-Centered Study of Perceptions of Subject Terms and Controlled Vocabulary," Cataloging \& Classification Quarterly 55, no. 7-8 (2017): 456-66, 
https://doi.org/10/gf7q5k; Matt Johnson, "Transgender Subject Access: History and Current Practice," Cataloging \& Classification Quarterly 48, no. 8 (2010): 661-83, https://doi.org/10/bxcvpx; Michèle Hudon, "Teaching Classification, 1990-2010," Cataloging \& Classification Quarterly 48, no. 1 (2010): 64-82, https://doi.org/10/bj9hzf; Sara A. Howard and Steven A. Knowlton, "Browsing through Bias: The Library of Congress Classification and Subject Headings for African American Studies and LGBTQIA Studies," Library Trends 67, no. 1 (2018): 74-88, https://doi.org/10/gfx5v5; J.L Colbert [ORCID: 0000-0001-5733-5168], "Comparing Library of Congress Subject Headings to Keyword Searches Involving LGBT Topics: A Pilot Study" (Master's Thesis, Champaign-Urbana, Illinois, University of Illinois Champaign-Urbana, 2017),

https://www.ideals.illinois.edu/handle/2142/97437; J. L. Colbert [ORCID: 0000-0001-5733-5168], “Coming out of the Controlled Closet: A Comparison of Patron Keywords for Queer Topics to Library of Congress Subject Headings," Library Philosophy and Practice, 2017, 23; James V. Carmichael, "Effects of the Gay Publishing Boom on Classes of Titles Retrieved Under the Subject Headings 'Homosexuality,' 'Gay Men,' and 'Gays' in the OCLC WorldCat Database," Journal of Homosexuality 42, no. 3 (April 2002): 65-88, https://doi.org/10/fs9vqx; Ben Christensen, "Minoritization vs. Universalization: Lesbianism and Male Homosexuality in LCSH and LCC," Knowledge Organization 35, no. 4 (2008): 229-38, https://doi.org/10/ggcjs6.

14 K. J. Rawson, "The Rhetorical Power of Archival Description: Classifying Images of Gender Transgression," Rhetoric Society Quarterly 48, no. 4 (August 8, 2018): 327-51, https://doi.org/10/gfkhvc; K J Rawson, "Accessing Transgender // Desiring Queer(Er?) Archival Logics," Archivaria 68, no. Fall (2009): 123-40. 15 Francis Nichols and Edwin M. Cortez, "Breaking Down the Barriers: Creating Empathetic Ontologies for LAMBDA Initiative," Tennessee Libraries 63, no. 1 (2013), https://www.tnla.org/page/529.

16 Kristine Nowak and Amy Mitchell, "Classifying Identity: Organizing an LGBT Library," Library Philosophy and Practice (e-Journal), January 1, 2016, https://digitalcommons.unl.edu/libphilprac/1452.

17 Christensen, "Minoritization vs. Universalization."

18 Colbert [ORCID: 0000-0001-5733-5168], "Coming out of the Controlled Closet: A Comparison of Patron Keywords for Queer Topics to Library of Congress Subject Headings"; Colbert [ORCID: 0000-0001-57335168], "Comparing Library of Congress Subject Headings to Keyword Searches Involving LGBT Topics: A Pilot Study."

19 Adler, Huber, and Nix, "Stigmatizing Disability"; Adler, "'Let's Not Homosexualize the Library Stacks"'; Adler, "The Case for Taxonomic Reparations"; Adler, "Transcending Library Catalogs."

20 Ornelas, "Queer as Folksonomies."

21 Rachel S Wexelbaum, "Global Promotion of LGBTQ Resources and Services through Social Media," Library

Faculty Publications 59 (2017): 18.

22 Jo Bates and Jennifer Rowley, "Social Reproduction and Exclusion in Subject Indexing: A Comparison of Public Library OPACs and LibraryThing Folksonomy," Journal of Documentation 67, no. 3 (April 26, 2011): 431-48, https://doi.org/10/bg43vm.

23 Patrick Keilty, "Sexual Boundaries and Subcultural Discipline," Knowledge Organization 39, no. 6 (2012): 419, https://doi.org/10/gfs7rr.

24 Tina Gross and Arlene G. Taylor, "What Have We Got to Lose? The Effect of Controlled Vocabulary on Keyword Searching Results," College \& Research Libraries 66, no. 3 (May 1, 2005): 212-30,

https://doi.org/10/ggw56t; Tina Gross, Arlene G. Taylor, and Daniel N. Joudrey, "Still a Lot to Lose: The Role of Controlled Vocabulary in Keyword Searching," Cataloging \& Classification Quarterly 53, no. 1 (2015): 1, https://doi.org/10/gft4kq.

25 Crystal A Vaughan, "The Language of Cataloguing: Deconstructing and Decolonizing Systems of Organization in Libraries," Dalhousie Journal of Interdisciplinary Management 14, no. Spring (2018): 3. ${ }_{26}$ Vaughan, "The Language of Cataloguing: Deconstructing and Decolonizing Systems of Organization in Libraries."

27 Emily Drabinski, "Queering the Catalog: Queer Theory and the Politics of Correction," The Library Quarterly 83, no. 2 (April 2013): 95, https://doi.org/10/f4rjgb.

28 Paige Crowl, "Queerly Categorized: LGBTQ+ Subjects and Language in the Catalog" (Class Paper,

Champaign, IL, University of Illinois Champaign-Urbana, 2018), 2, Illinoid IDEALS,

https://www.ideals.illinois.edu/handle/2142/101834.

29 Lorna Peterson, "Frances Lydia Yocom," Blog, Women of Library History, 2019, https://womenoflibraryhistory.tumblr.com/post/171930678333/frances-lydia-yocom; Zita Christina Nunes, "Remembering the Howard University Librarian Who Decolonized the Way Books Were Catalogued," 2018- 
11-2, Smithstonian Magazine, Smithsonian Magazine, https://www.smithsonianmag.com/history/remembering-howard-university-librarian-who-decolonizedway-books-were-catalogued-180970890/.

30 Melissa A. Adler, "The ALA Task Force on Gay Liberation: Effecting Change in Naming and Classification of GLBTQ Subjects," Advances in Classification Research Online 23, no. 1 (2012): 1-4,

https://doi.org/10.7152/acro.v23i1.14226; Sanford Berman and Tina Gross, "Expand, Humanize, Simplify: An Interview with Sandy Berman," Cataloging \& Classification Quarterly 55, no. 6 (2017): 347-60, https://doi.org/10.1080/01639374.2017.1327468; Sanford Berman, Joy of Cataloging (Oryx Press, 1981), https://agris.fao.org/agris-search/search.do?recordID=US201300399304; Sanford Berman, Subject Cataloging: Critiques and Innovations (Psychology Press, 1984). 31 Sanford Berman, "Personal LCSH Scorecard" (Sanford Berman, July 2016). 32 Carmichael, "Effects of the Gay Publishing Boom on Classes of Titles Retrieved Under the Subject Headings 'Homosexuality,' 'Gay Men,' and 'Gays' in the OCLC WorldCat Database"; Ellen Greenblatt, "AIDS Information in Libraries," in Gay and Lesbian Library Service, ed. Cal Gough and Ellen Greenblatt, 1990, 172-98; Gough and Greenblatt, Gay and Lesbian Library Service; Greenblatt, "Homosexuality: The Evolution of a Concept in the Library of Congress Subject Headings"; C. McClary and V. Howard, "From 'Homosexuality' to 'Transvestites': An Analysis of Subject Headings Assigned to Works of GLBT Fiction in Canadian Public Libraries," Canadian Journal of Information and Library Science 31, no. 2 (2007): 149-62; Sanford Berman, "Two Changed Headings:", Technical Services Quarterly 2, no. 1-2 (August 29, 1985): 155-65, https://doi.org/10/btxfnx. 33 K.R. Roberto, "Preface," in Radical Cataloging: Essays at the Front, ed. K. R. Roberto (Jefferson, N.C: McFarland \& Co, 2008), 1-3.

34 Jean Weihs, "A Review of 'Radical Cataloging: Essays at the Front,"' Cataloging \& Classification Quarterly 48, no. 4 (2010): 354-55, https://doi.org/10/bcn47n; Sandra Littletree and Cheryl A. Metoyer, "Knowledge Organization from an Indigenous Perspective: The Mashantucket Pequot Thesaurus of American Indian Terminology Project," Cataloging \& Classification Quarterly 53, no. 5-6 (2015): 640-57, https://doi.org/10/gf2d7j; Raegan Swanson, "Adapting the Brian Deer Classification System for Aanischaaukamikw Cree Cultural Institute," Cataloging \& Classification Quarterly 53, no. 5-6 (2015): 568-79, https://doi.org/10/gg3f5x; Alissa Cherry and Keshav Mukunda, "A Case Study in Indigenous Classification: Revisiting and Reviving the Brian Deer Scheme," Cataloging \& Classification Quarterly 53, no. 5-6 (2015): 548-67, https://doi.org/10/gf4f8j; Amelia Koford, "How Disability Studies Scholars Interact with Subject Headings," Cataloging \& Classification Quarterly 52, no. 4 (2014): 388-411, https://doi.org/10/gf542p. 35 Olson, "Thinking Professionals"; Suzhen Chen and Margaret Joyce, "Teaching a Cataloging/Metadata Course in a Changing World: Experience and Reflection," International Journal of Librarianship 4, no. 2 (2019): 11122, https://doi.org/10/gg3f5w.

36 Anna M. Ferris, "Birth of a Subject Heading," Library Resources \& Technical Services 62, no. 1 (January 2018): 16, https://doi.org/10/gfvmxr.

37 Ferris.

38 Toni Samek, Critical Librarianship: an interview with Toni Samek, interview by Tara Robertson, 2007, http://tararobertson.ca/2007/critical-librarianship-an-interview-with-toni-samek/.

39 Michelle Caswell and Marika Cifor, "From Human Rights to Feminist Ethics: Radical Empathy in the Archives," Archivaria 81, no. Spring (2016): 24-43; Violet B. Fox and Kelly Swickard, "My Zine Life Is My Private Life': Reframing Authority Control from Detective Work to an Ethic of Care," in Ethical Questions in Name Authority Control, ed. Jane Sandberg (Sacramento, CA: Library Juice Press, 2019), 19.

40 Violet B. Fox and Tina Gross, "Authority Work as Outreach," in Ethical Questions in Name Authority Control, ed. Jane Sandberg (Sacramento, CA: Library Juice Press, 2019), 337-51.

41 The Information Maintainers et al., "Information Maintenance as a Practice of Care," June 17, 2019, 14, https://doi.org/10/gf7q57.

42 Olson, "Thinking Professionals," 52.

43 Adler, Cruising the Library: Perversities in the Organization of Knowledge.

44 Psychopathia Sexualis, with Especial Reference to the Antipathic Sexual Instinct, a Medico-Forensic Study;

(New York: Rebman, 1886), http://archive.org/details/psychopathiasexu00krafuoft.

45 Online Etymology Dictionary, "Asexual: Origin and Meaning," Online Etymology Dictionary, accessed November 17, 2019, https://www.etymonline.com/word/asexual.

${ }_{46}$ Anthony F. Bogaert, Understanding Asexuality (Lanham, [Md.]: Rowman \& Littlefield Publishers, 2012). 
47 Library of Congress, "Cataloging Policy And Support Office: Five Year Progress Report on Subject Subdivisions Conference Recommendations," Progress Report (Washington, D.C: Library of Congress, December 1996), https://www.loc.gov/catdir/cpso/subdconf.html.

48 "What Is Asexuality?," What is Asexuality, 2019, AVEN, http://www.whatisasexuality.com/intro. 49 Jenna Freedman, "Zine - Taking the Cake: An Illustrated Primer on Asexuality," Lower East Side Librarian, March 30, 2014, https://jennafreedman.tumblr.com/post/81229535214/zine-taking-the-cake-anillustrated-primer-on.

50 Netanel Ganin, "New LCSH May Contain Trace Amounts of Nuts," I Never Metadata I Didn't Like (blog), July 13, 2016, https://inevermetadataididntlike.wordpress.com/2016/07/13/new-lcsh-11/.

51 Library of Congress, "Program for Cooperative Cataloging Homepage," webpage, accessed November 4, 2019, https://www.loc.gov/aba/pcc/.

52 "On With Your Headings! (Part One)," Blog, Concerned Archivists Alliance (blog), July 11, 2017.

53 Ganin, "New LCSH May Contain Trace Amounts of Nuts."

54 Library of Congress, "About - Cataloging and Acquisitions," April 3, 2019, https://www.loc.gov/aba/about/. 55 Ganin, "New LCSH May Contain Trace Amounts of Nuts."

56 Library of Congress, "Program for Cooperative Cataloging, Subject Authority Cooperative Program.

Summary of Decisions, Editorial Meeting Number 1603" (Washington, D.C: Library of Congress, 2016), https://www.loc.gov/aba/pcc/saco/cpsoed/psd-160321.html.

57 Jack Drescher, "Out of DSM: Depathologizing Homosexuality," Behavioral Sciences 5, no. 4 (December 4, 2015): 565-75, https://doi.org/10/ggdgzc; Robert E. Gould, "If It Isn't an Illness, What Is It?," The New York Times, February 24, 1974, sec. Archives, https://www.nytimes.com/1974/02/24/archives/what-we-dontknow-about-homosexuality-if-it-isnt-an-illness-what-is.html.

58 Netanel Ganin et al., "Asexuality_Asexual People Re-Submission.Docx" (Unpublished., April 2016); Ganin, "New LCSH May Contain Trace Amounts of Nuts."

59 Ganin et al., "Asexuality_Asexual People Re-Submission.Docx."

60 Ganin et al.

61 Ganin et al.

62 Ganin et al.

63 Netanel Ganin and Catherine Oliver, "On With Your Headings! (Examples)," Concerned Archivists Alliance (blog), July 13, 2017, https://concernedarchivists.wordpress.com/on-with-your-headings-examples/. 64 Ganin, "New LCSH May Contain Trace Amounts of Nuts."

65 Karli June Cerankowski and Megan Milks, eds., Asexualities: Feminist and Queer Perspectives, Routledge Research in Gender and Society 40 (New York; London: Routledge, Taylor \& Francis Group, 2014); Julie Sondra Decker, The Invisible Orientation: An Introduction to Asexuality (Carrel Books, 2014).

66 Library of Congress, “Cataloging Distribution Service Monthly List 1606," Classification Web, June 20, 2016, https://classweb.org/approved-subjects/1606.html; Ganin, "New LCSH May Contain Trace Amounts of Nuts." ${ }_{67}$ Netanel Ganin, "I Know We're Celebrating Right Now...," Twitter, July 13, 2016,

https://twitter.com/oponions/status/753305164077998080.

68 The Information Maintainers et al., "Information Maintenance as a Practice of Care."

69 The Information Maintainers et al.

70 Library of Congress, "SACO Funnels," Program for Cooperative Cataloging, June 26, 2020, https://www.loc.gov/aba/pcc/saco/funnels.html; Rebecca Culbertson and Brian E. C. Schottlaender, "The History and Development of the Program for Cooperative Cataloging," Cataloging \& Classification Quarterly 58, no. 3-4 (2020): 248-56, https://doi.org/10/gg3vt4; Michael Colby, "SACO: Past, Present, and Future," Cataloging \& Classification Quarterly 58, no. 3-4 (2020): 285-93, https://doi.org/10/gg3vt5.

71 Matthew Haugen and Amber Billey, "Building a More Diverse and Inclusive Cataloging Cooperative," Cataloging \& Classification Quarterly 58, no. 3-4 (2020): 382-96, https://doi.org/10/gg3vt6.

72 Anna Clutterbuck-Cook, "On With Your Headings! (Part One)," Concerned Archivists Alliance (blog), July 11, 2017, https://concernedarchivists.wordpress.com/2017/07/11/on-with-your-headings/.

73 Caswell and Cifor, "From Human Rights to Feminist Ethics: Radical Empathy in the Archives."

74 Michelle Caswell, Marika Cifor, and Mario H. Ramirez, "'To Suddenly Discover Yourself Existing':

Uncovering the Impact of Community Archives," The American Archivist 79, no. 1 (June 2016): 56-81, https://doi.org/10/gfc3hf. 


\section{Appendix}

First (rejected) proposal for "Asexual People" SUBJECT AUTHORITY PROPOSAL FORM FOR NON-PCC INSTITUTIONS

This form is for non-PCC institutions only. PCC institutions should use the Minaret Subject Proposal System for submitting subject authority proposals.

Complete this form, save it with a new name, and attach it to an email message to policy@loc.gov

Please consult the Subject Headings Manual (SHM), Instruction Sheet H 200, Preparation of Subject Heading Proposals, to complete the form. The SHM is available in Cataloger's Desktop, or can be downloaded from http://www.loc.gov/aba/ publications/FreeSHM/freeshm.html\#H0200.

008/06: (Direct or indirect geographic subdivision)

_ X__ (May Subd Geog) ___ (Not Subd Geog) ___ (No Decision)

053 :

150: Asexual people

450 (UF): Asexuals

450 (UF): Aces (Persons)

550 (BT): Sexual minorities

670 Work cat.: 2014948221: Decker, Julie Sondra. The Invisible orientation : an introduction to asexuality, 2014: \$b jacket (Julie Sondra Decker outlines what asexuality is, counters misconceptions, provides resources, and puts asexual people's experiences in context as they move through a very sexualized world.)

670 ("Sources found" to justify the heading or cross-references):

Asexualities feminist and queer perspectives, 2014: \$b summary (Asexuality is predominantly understood as an orientation describing people who do not experience sexual attraction.)

670 (additional "Sources found" to justify the heading or cross-references):

Asexuality Visibility \& Education Network WWW site, January 31, 2016: \$b home page (An asexual person is a person who does not experience sexual attraction).

What is Asexuality WWW site, January 31, 2016: \$b (Am I Ace? A teenager's Guide to Asexuality.)

675 (Sources not found):

781 (Geographic subdivision-for 151 headings only)

$\$ \mathrm{z}$

$\$ \mathrm{z}$ 
667 (Note field):

952 : 6 bib. records to be changed 952: LC pattern or SCM: Intersex people

Submitted by: Netanel Ganin

e-mail/phone: REDACTED

\section{Second (accepted) proposal for "Asexual People" SUBJECT AUTHORITY PROPOSAL FORM FOR NON-PCC INSTITUTIONS}

This form is for non-PCC institutions only. PCC institutions should use the Minaret Subject Proposal System for submitting subject authority proposals.

Complete this form, save it with a new name, and attach it to an email message to policy@loc.gov

Please consult the Subject Headings Manual (SHM), Instruction Sheet H 200, Preparation of Subject Heading Proposals, to complete the form. The SHM is available in Cataloger's Desktop, or can be downloaded from http://www.loc.gov/aba/ publications/FreeSHM/freeshm.html\#H0200.

008/06: (Direct or indirect geographic subdivision)

_ X__ (May Subd Geog) __ (Not Subd Geog) ___ (No Decision)

053 :

150: Asexual people

450 (UF): Asexuals

450 (UF): Aces (Persons)

550 (BT): Sexual minorities

670 Work cat:: 2014948221: Decker, Julie Sondra. The Invisible orientation : an introduction to asexuality, 2014: \$b jacket (Julie Sondra Decker outlines what asexuality is, counters misconceptions, provides resources, and puts asexual people's experiences in context as they move through a very sexualized world.)

670 ("Sources found" to justify the heading or cross-references):

Asexualities feminist and queer perspectives, 2014: \$b summary (Asexuality is predominantly understood as an orientation describing people who do not experience sexual attraction.)

$\mathbf{6 7 0}$ (additional "Sources found" to justify the heading or cross-references):

Asexuality Visibility \& Education Network WWW site, January 31, 2016: \$b home page (An asexual person is a person who does not experience sexual attraction). 
670 DeLuzio Chasin, CJ. "Theoretical Issues in the Study of Asexuality". Archives of Sexual Behavior, 2011: \$b abstract (Asexual people are those who experience little or no sexual attraction and/or who self-identify with asexuality)

670 DeLuzio Chasin, CJ. "Reconsidering Asexuality and its Radical Potential". Feminist Studies v. 39, no. 2, 2013: \$b page 406 (Some people prefer the term ace (a phonetic abbreviation of asexual) as a more inclusive alternative to the term asexual)

675 (Sources not found):

781 (Geographic subdivision-for 151 headings only) \$z

$\$ \mathrm{z}$

667 (Note field):

952 : 6 bib. records to be changed 952: LC pattern or SCM:

952: No specific concerns about this term were mentioned in the results of PSD meeting for list 1603. Re-submitting the proposal following the pattern of Bisexuals, but using Asexual people as the 150 and Asexuals as the 450 to prevent confusion with plants and animals.

Submitted by: Netanel Ganin

e-mail/phone: REDACTED

Revised (accepted) proposal for "Asexuality"

SUBJECT AUTHORITY PROPOSAL FORM FOR NON-PCC INSTITUTIONS

This form is for non-PCC institutions only. PCC institutions should use the Minaret Subject Proposal System for submitting subject authority proposals.

Complete this form, save it with a new name, and attach it to an email message to policy@loc.gov

Please consult the Subject Headings Manual (SHM), Instruction Sheet H 200, Preparation of Subject Heading Proposals, to complete the form. The SHM is available in Cataloger's Desktop, or can be downloaded from http://www.loc.gov/aba/ publications/FreeSHM/freeshm.html\#H0200.

008/06: (Direct or indirect geographic subdivision)

_ X__ (May Subd Geog) ___ (Not Subd Geog) ___ (No Decision)

053 :

150: Asexuality (Sexual orientation) 
450 (UF):

450 (UF):

550 (BT): Sexual orientation

670 Work cat.: 2014948221: Decker, Julie Sondra. The Invisible orientation : an introduction to asexuality, 2014: \$b jacket (Julie Sondra Decker outlines what asexuality is, counters misconceptions, provides resources, and puts asexual people's experiences in context as they move through a very sexualized world.) ; page 3 (Asexuality is a sexual orientation currently estimated to describe 1 percent of the population. Asexuality is usually defined as the experience of not being sexually attracted to others.)

670 ("Sources found" to justify the heading or cross-references):

Asexualities feminist and queer perspectives, 2014: \$b summary (Asexuality is predominantly understood as an orientation describing people who do not experience sexual attraction.)

670 Asexuality Visibility \& Education Network WWW site, Jan. 31, 2016.

670 Storms, Michael D. "Theories of Sexual Orientation." Journal of Personality and Social Psychology 38, no. 5, 1980, 783-92. doi:10.1037/0022-3514.38.5.783: \$b page 785 ([A] twodimensional map of erotic orientation produces four sexual-orientation categories: asexual, heterosexual, homosexual, and bisexual.)

670 Van Houdenhove et al. "Asexuality: A multidimensional approach". Journal of Sex Research, 2015: \$b page 669 (Asexuality is usually defined as a lack of sexual attraction (Bogaert, 2004), which is in line with the definition proposed by the asexual community stating that 'an asexual person is a person who does not experience sexual attraction' (http://www.asexuality.org).)

675 (Sources not found):

781 (Geographic subdivision-for 151 headings only) \$z

$\$ \mathrm{z}$

667 (Note field):

$952: 3$ bib. records to be changed 952: LC pattern or SCM: Heterosexuality, Homosexuality, Bisexuality

952: To address the concerns raised in the PSD meeting for list 1603: In re-submitting the proposal, all literature found states that asexuality is a sexual orientation. Asexuality is defined by a lack of sexual attraction but not necessarily by a lack of sexual behavior. Sex was suggested as a BT; however, because Asexuality is defined as a sexual orientation, not a behavior, we used the model of Homosexuality to determine that the BT Sexual orientation is a better fit. The suggestion of qualifying the term to distinguish from Asexuality in plants or other animals is a good one and has been done.

Submitted by: Catherine Oliver

e-mail/phone: REDACTED 